\title{
https://doi.org/10.30853/filnauki.2020.12.11
}

\section{Чжу Юньпин}

Эмотивность в современной письменной офрцциально-деловой коммуникации на русском

языке

Цель исследования - доказать существование эмоциональных и эмотивных компонентов в официально-деловом речевом жанре благодарственного письма. Научная новизна заключается в выявлении особенностей вербальной реализации категории эмотивности в эмоциогенном речевом жанре благодарственного письма в современном официально-деловом общении на русском языке, а также в установлении его вариативности в зависимости от особенностей воплощения в нѐм категории эмотивности и в выявлении его вторичной функции. В результате доказано, что степень интенсивности выражения категории эмотивности в жанре благодарственного письма обусловливает его официальный или полуофициальный статус. Отмечена также вторичная - рекламная - функция текстов данного жанра в официально-деловой коммуникации.

Адрес статьи: www.gramota.net/materials/2/2020/12/11.html

\section{Источник}

Филологические науки. Вопросы теории и практики

Тамбов: Грамота, 2020. Том 13. Выпуск 12. С. 57-60. ISSN 1997-2911.

Адрес журнала: www.gramota.net/editions/2.html

Содержание данного номера журнала: www.gramota.net/materials/2/2020/12/

\section{() Издательство "Грамота"}

Информация о возможности публикации статей в журнале размещена на Интернет сайте издательства: www.gramota.net Вопросы, связанные с публикациями научных материалов, редакция просит направлять на адрес: phil@gramota.net 
Список источников

1. Анненкова Е. И. Жанровое новаторство басен И. А. Крылова // Русская литература. XIX век. От Крылова до Чехова / сост. Н. Г. Михновец. СПб.: Паритет, 2001. С. 7-17.

2. Аристотель. Сочинения: в 4-х т. / пер. с древнегреч.; общ. ред. А. И. Доватура. М.: Мысль, 1984. Т. 4.830 с.

3. Арутюнова Н. Д. Метафора и дискурс // Теория метафоры: сборник / пер. с англ., фр., нем., исп., польск. яз.; вступ. ст. и сост. Н. Д. Арутюновой; общ. ред. Н. Д. Арутюновой, М. А. Журинской. М.: Прогресс, 1990. С. 5-32.

4. Гак В. Г. Метафора: универсальное и специфическое // Метафора в языке и тексте / отв. ред. В. Н. Телия; АН СССР, Ин-т языкознания. М.: Наука, 1988. С. 11-26.

5. Крылов И. А. Басни. М.: Эксмо, 2019. 352 с.

6. Лакофф Дж., Джонсон М. Метафоры, которыми мы живем. М.: УРСС Эдиториал, 2004. 256 с.

7. Литературная энциклопедия: словарь литературных терминов [Электронный pecypc]. URL: http://feb-web.ru/ feb/slt/abc/ (дата обращения: 31.08.2020).

8. Степанов Н. Л. И. А. Крылов. Жизнь и творчество. М.: Гос. издат. худож. лит., 1958. 468 с.

9. Чарыкова О. Н. Глагол как средство речевого воздействия // Речевое воздействие: сб. науч. тр. Воронеж: ЦентральноЧерноземное книжное издательство, 2000. С. 12-13.

10. Шмелев А. Д. Русская языковая модель мира: материалы к словарю. М.: Языки славянской культуры, 2002. 224 с.

\title{
Specific Features of Animal Metaphor in I. A. Krylov's Fables
}

\author{
Xu Zhengyu \\ Wang Lele \\ Peoples' Friendship University of Russia, Moscow \\ xzyu3121@163.com;2514751775@qq.com
}

\begin{abstract}
The study aims to determine specific features of animal metaphors in I. A. Krylov's fables. The article clarifies distinctive features of wolf, fox, lion, dog and donkey images, provides a structural analysis of metaphorical images, describes their characteristics. The research is novel in that it identifies the predominant way of metaphorical transfer, as well as a productive model of its creation. As a result, it was proved that the majority of indirect nominations in I. A. Krylov's fables are based on contrasting human and animal behaviour, and the unique feature of conveying a moral lesson to the reader is built on reinterpretation of the verbal component of a metaphor - on predicativity.
\end{abstract}

Key words and phrases: I. A. Krylov's fables; animal metaphor; predicativity; metaphorical images.

Цель исследования - доказать существование эмоциональных и эмотивных компонентов в официальноделовом речевом жанре благодарственного письма. Научная новизна заключается в выявлении особенностей вербальной реализации категории эмотивности в эмочиогенном речевом жанре благодарственного письма в современном официально-деловом общении на русском языке, а такюе в установлении его вариативности в зависимости от особенностей воплощения в нём категории эмотивности и в выявлении его вторичной функиии. В результате доказано, что степень интенсивности выражения категории эмотивности в жанре благодарственного письма обусловливает его официальный или полуофициальный статус. Отмечена также вторичная - рекламная - функция текстов данного жанра в официально-деловой коммуникации.

Ключевые слова и фразы: эмотивность; эмотема; официально-деловое общение; благодарственное письмо; стилевая контаминация.

\section{Чжу Юньпин \\ Санкт-Петербургский государственньй университет 2763496449@qq.com}

\section{Эмотивность в современной письменной официально-деловой коммуникации на русском языке}

В русской стилистике среди базовых черт официально-деловой коммуникации неизменно выделяется «объективность, направленная на обезличивание словесных конструкций», подчёркивается недопустимость эмоциональности в официально-деловой речи $[5$, с. 65]. Однако, «будучи мотивационной основой сознания и языкового поведения homo loquens, эмоции становятся неизменным участником их речевого взаимодействия» [11, с. 24], причём сегодня наблюдаются активные процессы «непрерывной и глобальной эмоционализации и экспрессивизации коммуникативного пространства во всех сферах нашей жизни» [Там же], включая официально-деловую: «...в современной русской лингвокультуре наметилась тенденция в публичном общении к ослаблению категоричности и официальности» $[10$, с. 28$]$. 
Актуальность темы исследования обусловлена недостаточной изученностью реализации категории эмотивности в официально-деловом общении и тем, что в данной сфере коммуникации функционирует немалое количество речевых жанров, содержание которых непосредственно сопряжено с эмоциями (поздравления, жалобы и др.). Сказанным определён и выбор конкретного материала для анализа - официальные благодарственные письма на торжественных бланках, где тема - благодарность - это «аффективно-эмоциональное состояние, которое подтверждает, что индивиды будут претерпевать свою привязанность или принадлежность к непосредственной эмоциональной связи и более длительной социальной связи» [9, с. 107].

Для достижения поставленной цели решаются следующие задачи: а) рассмотреть особенности структурносмысловой организации отобранных для анализа благодарственных писем, выделить в них компоненты, непосредственно выражающие эмоции адресанта; б) выделить и характеризовать средства воплощения в благодарственных письмах категории эмотивности: прежде всего, языковые, а также паралингвистические и визуальные; в) предложить коммуникативно-прагматическую классификацию речевого жанра благодарственного письма в современном официально-деловом общении на русском языке с учётом вариантов реализации в нём категории эмотивности.

Основными методами нашего исследования выступают коммуникативно-прагматический, композиционный и контекстуальный анализ.

Теоретической базой исследования послужили, прежде всего, труды отечественных авторов: М. В. Белякова [1], М. Я. Блоха и Н. А. Резниковой [2], В. И. Болотова [4], Т. В. Лариной [7], В. И. Шаховского [11], в которых категория эмотивности получает комплексную интерпретацию с учётом экстралингвистических и лингвистических факторов.

Практическая значимость исследования заключается в том, что его результаты могут быть использованы в курсах по русской стилистике, культуре речи, в живом официально-деловом общении, а также в обучении иностранцев русскому языку.

Категория эмотивности определяется нами, вслед за Т. В. Лариной, как сознательная, запланированная в коммуникации демонстрация эмоций, направленная на адресата [7, с. 119], которая может выражаться в письменном общении собственно вербальными средствами, то есть на лексическом уровне - эмотивной лексикой всех типов: эмотивами-номинативами (лексика, непосредственно называющая эмоции); эмотивами-ассоциативами (слова, которые могут вовсе не содержать эмоциональный компонент в своем значении, однако их эмоциональность связана с реакциями, ассоциациями, возникающими и затрагивающими как лично говорящего, так и слушающего); эмотивами-экспрессивами (слова, выражающие эмоциональную оценку) [2, с. 14-19], на синтаксическом уровне - эмотивными высказываниями, с помощью которых коммуникант может выразить свои эмоции [1, с. 126]; а также такими паралингвистическими средствами, как знаки пунктуации, специальные графические маркеры (например, эмодзи или тип и размер шрифта) и другие визуальные средства (например, цвет). По мнению В. И. Шаховского, положительная эмотивность «соответствует экологичным и конструктивным тексту и коммуникации» и оказывает положительное воздействие на поведение человека [11, с. 28].

В анализируемых текстах номинация их жанра - благодарственное письмо - эксплицитно выражает эмотему «благодарность». Эмотема определяется нами, вслед за В. И. Болотовым, как эмоционально заряженный фрагмент текста (от слова до всего текста), смысл или форма выражения содержания которого являются источником эмоционального воздействия [4, с. 18]. Следовательно, обозначение автором текста жанра своего высказывания не только отражает испытываемое им чувство, но и через воздействие эмотемы порождает новую эмоциогенную ситуацию действительности, вызывая у адресата ещё перед чтением целого текста благодарственного письма положительные эмоции, которые поддерживаются и специальным торжественным оформлением бланка. Иными словами, официальное благодарственное письмо (особенно торжественно оформленное) по определению является высказыванием (вербальным или поликодовым) с эмотивной доминантой, в том числе и в официально-деловом общении.

Как текстовый документ официально-делового стиля, благодарственное письмо обладает устойчивой модульной композицией и высокой речевой формулярностью. Оно обязательно включает располагающиеся по установленным канонам модули обозначения реквизитов адресата и адресанта и речевую формулу, передающую адресату осмысленное чувство благодарности адресанта.

Обратимся непосредственно к анализу текстов и рассмотрим три благодарственных письма на торжественных бланках, размещённые на официальном сайте пензенского ООО «Региональный полиграфический комбинат» (РПК) [12].

В тексте 1 для передачи благодарности используется стилистически нейтральный вне контекста глагол благодарить, который употреблён в форме третьего лица единственного числа в речевой формуле кто благодарит кого за что, проявляющей официально-деловую окраску за счёт стилистически маркированных номинаций коммуникантов: субъект благодарности назван словосочетанием администрация МАУ «Пензенский зоопарк», а адресат - словосочетанием генерального директора ООО «Региональный полиграфический комбинат» Тумасова Валерия Дмитриевича, где официально-деловой стиль высказывания подчёркивается и наличием в обеих приведённых номинациях обозначения должностных статусов коммуникантов (администрация - генеральный директор), и предшествованием в номинации адресата фамилии его имени и отчеству, и персонализацией собирательного субъекта администращия в завершающем модуле текста - расшифровке подписи адресанта - директор $A$. А. Воскресенский. Использование синекдохи в номинации адресанта и адресата - назывании глав фирм вместо их коллективов - характерный приём официально-делового общения. 
Позиция за что в указанной выше конструкции заполняется номинацией основания благодарности - за помощь в организации праздника, где используется цепочка существительных со значением действия, свойственная книжно-письменной речи, в частности текстам официально-делового стиля. И хотя при глаголе благодарить употреблён эмотив-номинатив (наречие образа действия) искренне, словосочетание искренне благодарить имеет официально-формулярный характер, и, таким образом, проанализированное благодарственное письмо 1 демонстрирует, что «официальность является важным сдерживающим условием для свободного и полного выражения искренних эмоций, требует обращения к специальным приемам речевого поведения, определяющим выбор уместной формулы выражения чувств» [6, с. 58].

В отличие от сугубо официального благодарственного письма 1, анализируемый текст 2 демонстрирует расширенную реализацию категории эмотивности, в целом так же, как и текст 1, оставаясь в рамках норм официально-делового общения, проявляющихся и в специфическом способе номинации адресата - коллективу ООО «Региональный полиграфический комбинат» и лично директору Тумасову Валерию Дмитриевичу, и в использовании официальных речевых формул как для передачи благодарности: ВЫРРАЖАЕМ ОГРОМНУЮ БЛАГОДАРНОСТЬ, так и для экспликации её оснований: за участие в благотворительной программе, за неравнодушное отношение.

Но в отличие от текста 1 , текст 2 отступает от строгого соблюдения норм официально-делового общения. Отделение начальной части речевой формулы благодарности: ВЫРАЖАЕМ ОГРОМНУЮ БЛАГОДАРНОСТЬ! - восклицательным знаком от далее следующих номинаций адресата и оснований благодарности превращает последние два из названных компонентов в парцеллят. Так уже первая строка письма получает эмоционально-экспрессивную окраску, что проецируется и на последующий текст.

Формированию эмоциональной экспрессии в письме способствует и повторное выражение благодарности с использованием стилистически нейтральной конструкции: Спасибо Вам. Здесь номинация адресата при помощи вежливой формы личного местоимения, а также отсутствие в начальной формуле благодарности институционального обозначения адресанта при импликации в ней коллективно-персонального субъекта благодарности через определённо-личную форму сказуемого - глагола 1-го лица множественного числа (выражаем) вносят в данное официальное благодарственное письмо личностное начало, которое поддерживается и употреблением завершающей письмо личностно ориентированной формулы вежливости С уважением.

Эмоционально-экспрессивная окраска и личностная ориентация изложения проявляются в тесте 2 и в факультативном для благодарственного письма модуле пожелания, выраженного здесь эллиптическим восклицательным предложением с номинациями-эмотемами успехов и благополучия и притяжательным вежливым местоимением 2-го лица в функции определения: УСПЕХОВ И БЛАГОПОЛУЧИЯ ВАШЕЙ ОРГАНИЗАЦИИ! Таким образом, благодарственное письмо 2 демонстрирует контаминацию черт институционального и личностно ориентированного общения, что отражает переход от собственно официально-делового к полуофициальному регистру общения, которое характеризуется как «общение статусно-ролевое, асимметричное, профессионально насыщенное», но с ориентацией на непринуждённость, что проявляется в контаминации норм официально-деловой и разговорной речи [3, с. 18].

Ярким примером полуофициального благодарственного письма является текст 3, который представляет собой благодарственное письмо Пензенской региональной общественной организации «Федерация спорта лиц с поражением опорно-двигательного аппарата», написанное в 1-м лице единственного числа от имени руководителя организации (существующая традиция позволяет с уверенностью высказать предположение об адресанте, хотя его личная подпись в конце текста не имеет расшифровки) и адресованное, в первую очередь, лично директору ООО «Региональный полиграфический комбинат», о чём свидетельствует вежливая официальная формула личного обращения: Уважаемый Валерий Дмитриевич! Кроме названия жанра (благодарственное письмо) и указанного обращения, в данном благодарственном письме лишь первое предложение отвечает нормам официально-делового стиля: Выражаю БЛАГОДАРНОСТЬ коллективу РПК.

Дальнейший текст письма находится в резком стилистическом контрасте с начальной частью. Он содержит повторное выражение благодарности (Говорю СПАСИБО ВАМ, Искреннее и БОЛЬШОЕ!), комплиментов (ВЫ несете людям радость / Точно в срок, наверняка. / ВАШЕ дело благородно, / а ассортимент богат, / сделаете что угодно, / чтоб клиент всегда был рад; ВЫ ДОБРЫ, КРАСИВЫ, а ВАШЕ СЕРДЦЕ ЗОЛОТОЕ!!!), пожеланий (Пусть же с ВАМИ СЧАСТЬЕ будет, / И сопутствует УСПЕХ, / Блага ВАМ и проиветайте, / СЕРДЦЕМ и ДУШОЙ творите, / новых иелей достигайте), изложенных в рифмованных высказываниях, не обладающих, как видно из приведённых примеров, высокими художественными достоинствами, но отличающихся эмоциональной насыщенностью, передаваемой не только лексикой и фразеологией восторженного содержания, но и шрифтовыми выделениями, а также утроением восклицательных знаков, подчёркивающих интенсивность испытываемых адресантом позитивных чувств.

С первого взгляда обращает на себя внимание и отличие бланка третьего благодарственного письма от бланков двух вышерассмотренных писем: он выглядит менее официальным, в первую очередь, потому, что на нем нет изображения герба Российской Федерации. При этом его красочное оформление выполнено, как и у других писем, при помощи сочетания ярких цветов с учетом того, что «цвет способен не только вызывать у человека соответствующую реакцию, но и определенным образом формировать его эмоции, радость (веселье): особое предпочтение вызывают энергонасыщенные (желтый и красный)...» [8].

Таким образом, в ходе работы сделаны следующие выводы: выявленные особенности реализации категории эмотивности убедительно доказывают, что в официально-деловой коммуникации имеет место выражение 
эмоций, это говорит об определенной тенденции к снижению формализации делового общения. Рассмотренный жанр благодарственного письма на торжественно оформленном бланке в сегодняшнем деловом общении на русском языке функционирует как в строго официальном стилевом регистре, где эмотивность рационализирована, выражена соответствующими устоявшимися речевыми формулами, так и в полуофициальных коммуникативных вариантах, основанных на разной степени сочетания официальной и непринуждённой тональностей речи, а следовательно, на разных уровнях интенсивности экспрессии при передаче эмоций.

Иными словами, степень интенсивности выражения категории эмотивности в жанре благодарственного письма обусловливает его официальный или полуофициальный статус. В сугубо официальном благодарственном письме рационализированная эмотивность отражается в норме стабильной композицией и передающими позитивные эмоции адресанта устойчивыми эмоционально не окрашенными речевыми формулами. В благодарственном письме полуофициального характера в целом сохраняются нормы официальноделового стиля при номинации адресата и экспликации оснований благодарности, но вместе с тем появляются дополнительные композиционные элементы, такие как комплименты и пожелания адресату, для выражения которых используются эмоционально окрашенные языковые единицы разных уровней и паралингвистические средства. Такая стилевая контаминация вносит в официальные благодарственные письма личностное начало, чем усиливает их эмоционально-оценочный воздействующий потенциал.

Также было выявлено, что благодарственные письма (особенно написанные на торжественно оформленных бланках) широко используются организациями-получателями во вторичной (рекламной) функции, в связи с чем для демонстрации вывешиваются на стенах офисов и публикуются на интернет-сайтах в целях рекламирования высокого качества товаров и услуг организации-получателя и формирования её позитивного делового имиджа у потенциальных клиентов и партнёров через эмоциональное воздействие. Полученные нами выводы позволяют создать типологическое описание официально-деловых текстов с эмотивной доминантой в дальнейших исследованиях и рассмотреть другие тексты, существующие на стыке официально-делового стиля и рекламного и сравнить их с благодарственными письмами.

Список источников

1. Беляков М. В. Характер эмотивности дипломатического дискурса // Вестник Российского университета дружбы народов. Серия «Лингвистика». 2015. № 2. С. 124-132.

2. Блох М. Я., Резникова Н. А. Средства эмоционального воздействия политических выступлений // Вестник Томского государственного педагогического университета. 2006. № 9. С. 14-19.

3. Бобарыкина Н. А. Общение в малой социальной группе: автореф. дисс. ... к. филол. н. Саратов, 2003. 19 с.

4. Болотов В. И. Эмоциональность текста в аспектах языковой и неязыковой вариативности: основы эмотивной стилистики текста. Ташкент: Фан, 1981. 116 с.

5. Жукова Е. А. Особенности официально-делового стиля // Вестник Московского информационно-технологического университета - Московского архитектурно-строительного института. 2018. № 1. С. 65-67.

6. Ионова С. В., Чжан К. Рационализация эмоций в этикетных ситуациях общения // Эмоциональная сфера человека в языке и коммуникации: синхрония и диахрония: материалы Международной конференции. М. - Ярославль: Канцлер, 2018. С. 56-69.

7. Ларина Т. В. Категория вежливости и стиль коммуникации: сопоставление английских и русских лингвокультурных традиций. М.: Языки славянских культур, 2009. 512 с.

8. Петренко В. Ф., Кучеренко В. В. Взаимосвязь эмоций и цвета [Электронный pecypc]. URL: https://shust.me/ vzaimosvyaz-emotsij-i-tsveta/ (дата обращения: 04.09.2020).

9. Симонова О. А., Канто-Мила Н. Благодарность как невидимая сила, связывающая общество // Социальные и гуманитарные науки. Отечественная и зарубежная литература. Серия 11. Социология. Реферативный журнал. 2013. № 2. C. 101-112.

10. Хорохордина О. В. Поликодовые реализации инструктивных речевых единиц: типологический аспект // Мир русского слова. 2016. № 4. С. 1-29.

11. Шаховский В. И. Диссонанс экологичности в коммуникативном круге: человек, язык, эмоции: монография. Волгоград: ИП Поликарпов И. Л., 2016. 504 с.

12. https://penzarpk.ru/klienty-o-nas.html (дата обращения: 08.10.2020).

\title{
Emotivity in the Modern Russian Official Written Discourse
}

\author{
Zhu Yunping \\ Saint Petersburg University \\ 2763496449@qq.com
}

The paper aims to prove presence of emotional and emotive components in the official speech genre of a grateful letter. The author reveals peculiarities of the emotivity category realization in the emotion-generative speech genre "grateful letter" of the modern Russian official written discourse, shows how this genre varies depending on specificity of the emotivity category representation, identifies the secondary function of the "grateful letter" genre texts, which constitutes scientific originality of the study. The research findings are as follows: the author proves that the level of emotivity of a grateful letter determines its official or semi-official status. The secondary (advertising) function of such texts in official communication is also revealed.

Key words and phrases: emotivity; emoteme; official communication; grateful letter; stylistic contamination. 